\title{
A question of trust
}

\author{
It isn't enough to explain the facts of climate change very, very clearly. Building public trust requires \\ researchers to change their practices.
}

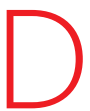
espite the scandals over leaked e-mails at the University of East Anglia, UK, and flawed data in the most recent assessment from the Intergovernmental Panel on Climate Change (IPCC), the scientific evidence for global warming remains strong. The question, then, is to what extent have the controversies eroded the public's trust in climate science or, worse, in the scientists themselves?

There has undoubtedly been some slippage. But a closer look at the data across multiple polls shows that, broadly speaking, the public trusts scientists, believes in global warming and wants governments to do something about it (see page 24). The public seems to have done what the mainstream media could not: it has kept the scandals in perspective. The scathing verbal attacks on climate science and scientists are actually coming from a relative handful of critics, and they do not reflect a broader resurgence of scepticism.

Yet few climate scientists are likely to take satisfaction in this news. For them, the real measure of public trust is the level of political engagement on global warming: if people truly believe the science, then why have so few of them demanded action of their governments? Why is the world still at loggerheads over climate change?

The problem is that people assess information from any number of sources, not just scientists. And people - politicians included make decisions on the basis of self-interest and their own hopes, fears and values, which will not necessarily match what many researchers deem self-evident.

The scientific community must recognize that the issues surrounding climate change resonate with the public and politicians on many different levels. Facts do matter. Scientists must continue to engage the public in plain language whenever possible, laying out the evidence for climate change in a clear and compelling way. And they must provide policy-makers in both the public and private sectors with accurate, credible and timely information (see page 30 ). But, given the complexity of that evidence, and the many uncertainties that remain, scientists will be only as persuasive as they are trusted which means that preserving and cultivating the public's trust must be the scientific community's top priority.

As the recent controversies have made abundantly clear, individual researchers must learn to see themselves as public figures and honest brokers. In particular, they must recognize that questionable data management and improper restrictions on the release of data - or on the details of how those data were processed - undermine both public confidence and scientific integrity by impeding "Researchers must learn to see themselves as public figures and honest brokers." independent expert assessment.

More generally, scientists, institutions and funding agencies must increase transparency wherever possible. When engaging the public, the kind of uncertainties and internal debates that scientists struggle with on a daily basis should be played up, not down (see page 31). Likewise, neither the IPCC nor national governments should endorse regional studies that overstate scientists' ability to forecast the local effects of climate change on short timescales.

Finally, scientists must steer clear of hype and rein in exaggerations about the threat of global warming. Those who seek to sow doubt about the solid and widespread evidence for global warming must be countered with facts as a matter of course. But legitimate fears and scientific scepticism must be welcomed into the discussion.

The science isn't complete and never will be, but it is sufficiently robust that broad conclusions cannot be undermined by questions about any given datum point. From this perspective, the fact that climate scientists can't predict exactly how bad the impacts might be could well be the best argument for action.

\section{Order from chaos}

\section{Much tighter regulations are needed to reap the full benefits of stem-cell treatments.}

S tem-cell therapy is nothing new. The transplantation of bone marrow to treat blood cancers such as leukaemia and lymphoma has existed for decades: the therapy works because marrow contains blood-forming stem cells that can replace the cells being destroyed.

But the stem cells involved in such treatments simply continue to perform their natural function. What is new - and concerning is a trend towards transplants in which the stem cells are expected to behave in different ways, even though there is little empirical evidence to suggest that they can do so. The perils of that approach were highlighted last week, when researchers reported the discovery of strange lumps of cells in the kidney of a woman who had undergone stem-cell treatment in Thailand (see Nature 465, 997; 2010). In another case last year, an Israeli boy developed tumours after being injected several times in a Moscow hospital with what was later determined to be a slurry of mixed fetal tissues.

There are at present estimated to be more than 200 clinics worldwide - including more than 100 in China alone - offering what are often unproven stem-cell treatments for scores of disorders including spinal-cord injury, amyotrophic lateral sclerosis and multiple sclerosis (see Nature 459, 146-147; 2009). The potential profits are huge: there is an abundance of patients desperate for miracle cures, and one stem-cell treatment can bring in tens of thousands of US dollars.

Practitioners at these clinics claim that their treatments are safe and effective. But they typically base those claims on little more than 
patient testimonials and media accounts, and they lack independent oversight. Few offer evidence from controlled clinical studies or from rigorous follow-up of their own patients.

Government regulation of stem-cell clinics has so far been inconsistent - and is difficult in any case, owing to their cross-border appeal. But two non-governmental organizations have now started offering information to help patients navigate the flood of nonsense and half-truths. In April, the International Cellular Medicine Society (ICMS), a group of 224 doctors and researchers based in Portland, Oregon, started an 'open treatment registry' intended to act as a clearing house for patient and clinician testimony (see Nature Med. 16, 495; 2010). The ICMS also accredits clinics that "provide complete disclosure of their collection, processing and re-implantation procedures, as well as all outcomes and complications data from patients they have treated".

In principle, this represents a step in the right direction. But the ICMS needs to be rigorous about requiring clinical-trial data for the therapies offered by the clinics it certifies, working with regulatory agencies and demanding that patient follow-up be carried out by independent third parties. It should also insist that its member clinics put some of their profits towards testing their protocols rigorously while thoroughly examining unexpected outcomes.

The primacy of such research is at the heart of another organization's mission. In June, the International Society for Stem Cell Research (ISSCR), a group of stem-cell biologists and clinicians based in Deerfield, Illinois, launched a website (see go.nature.com/ zK3L4e) with its own evaluations of stem-cell therapies, including a list of questions for patients to ask their doctors. Visitors to the site are briefed on the role of publication, peer review and clinical trials in turning science into medicine. They can also submit prospective clinics and treatments for an ISSCR review, which will include a check of a clinic's ethical, regulatory and safety records.

To be considered credible, the ISSCR and ICMS must identify, and be transparent in dealing with, potential conflicts of interest. The ISSCR has made a good start, vowing to eject from the society members who are affiliated with clinics that offer unproven stem-cell treatments.

The medical promise of stem cells remains real, but largely unrealized for now. The excitement must not be left to dissolve into a muddle of disappointment, frustration and fear because of the practices of a few irresponsible profiteers.

\section{When blogs make sense}

\section{Biologists and astronomers approach data sharing differently, but both need better public outreach.}

A stronomers are busier than ever: "I look at our students and ... there's less understanding and more rushing ... we're caught up in this rat race and I don't know what we're chasing." Biologists too: "Technology has made me one of the most highly paid, under-talented secretaries on campus. I have to do a lot more than I've ever had to do before, badly."

These quotes come from Assessing the Future Landscape of Scholarly Communication (go.nature.com/6Y4b1g), a survey of 160 academics published earlier this year by Diane Harley and her colleagues in the Center for Studies in Higher Education (CSHE) at the University of California, Berkeley. The quotes are representative of academic scientists these days, thanks not least to the unrelenting pressure to publish.

In the two major scientific disciplines covered by the study - biology and astronomy - peer-reviewed publications continue to be the primary markers of academic achievement. But the survey also found regrettable disparities between the two disciplines in less-formal peer-to-peer communication. The astronomy community effectively publishes by preprint. The process of formal publication is seen as a necessary step for the record, and formal peer review adds some value. But the preprint server arXiv.org is a highly trusted forum by which one can deposit the original version of a paper, thereby logging one's priority in a competitive area, and also receive private comments by e-mail that can complement the formal peer-review process. Respondents judge the level of error in astronomy preprints to be low.

Biologists tend to avoid such open sharing of first drafts. They acknowledge that the vastness of their community and its acute competitiveness make them reluctant to act in such a trusting fashion. That's regrettable, because it seems from astronomers' accounts that open sharing on preprint servers improves the standards of the literature.

But deposition in arXiv is about as far as the scientific openness of even astronomers goes. The discussion that ensues is private. As Nature's experiment in open peer review showed (go.nature.com/ $\mathrm{N} 67 \mathrm{mFk}$ ), and as can be seen from the lack of commenting on papers in Nature and other journals that encourage it, researchers see little to be gained from open discourse before or after publication. Not only are they busy, as the above quotes attest, but there's no credit to be gained, and some risk if one makes an erroneous or critical statement in public. What is more, astronomers and biologists register active discouragement of blogging - a form of communication that in their eyes carries no stamp of reliability or prestige. That picture of resistance to interactive discussion of science on the Internet is further amplified in a new survey, If You Build It, Will They Come? How Researchers Perceive and Use Web 2.0, to be published later this month by the UK Research Information Network.

However, the astronomers and biologists interviewed in the CSHE survey expressed strong support for outreach and engagement, stating that they enjoyed giving public talks and contributing opinions to mass media. Here, surely, is an opportunity for blogging - or at least, for consistently displaying one's research in a comprehensible fashion on a lab website - to acquire value and peer recognition.

Institutions need to recognize and to encourage such outreach explicitly - not just as a matter of routine, but specifically highlighting and promoting it at times of relevant public debate or when the interests and voices of scientists need to be promoted. Web 2.0 doesn't yet have what it takes to add significant value to open academic discourse, but it can surely make a difference to the public accessibility of science. 